\title{
Mini Review of Prostate Cancer Diagnostics
}

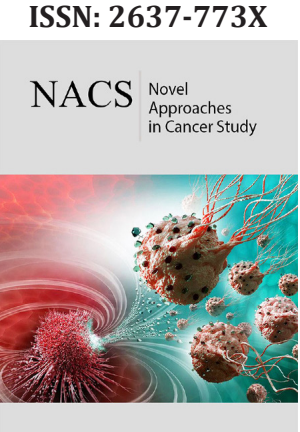

*Corresponding author: Besarion Partsvania, Georgian Technical University, Institute of Cybernetics, Tbilisi, Georgia

Submission: 进 October 23, 2019

Published: 僵 November 14, 2019

Volume 3 - Issue 5

How to cite this article: Besarion Partsvania, Tamaz Sulaberidze, Alexandre Kuskivadze, Sophia Abazadze. Mini Review of Prostate Cancer Diagnostics. Nov Appro in Can Study. 3(5). NACS.000573.2019.

DOI: 10.31031/NACS.2019.03.000573

Copyright@ Besarion Partsvania, This article is distributed under the terms of the Creative Commons Attribution 4.0 International License, which permits unrestricted use and redistribution provided that the original author and source are credited.

\author{
Besarion Partsvania ${ }^{1 *}$, Tamaz Sulaberidze ${ }^{1}$, Alexandre Kuskivadze ${ }^{2}$ and Sophia \\ Abazadze ${ }^{2}$ \\ ${ }^{1}$ Georgian Technical University, Institute of Cybernetics, Georgia \\ ${ }^{2}$ Department of Urology, Tbilisi State Medical University, Georgia
}

\section{Introduction}

According to the World Health Organization (WHO) prostate cancer is the second cause of cancer death in men worldwide [1,2]. Some advanced prostate cancers have well known symptoms. However non-cancerous diseases of the prostate, such as benign prostatic hyperplasia (BPH) cause same symptoms. On the other hand, at very early stages, prostate cancer has no symptoms, the tumor dimension is quite small, and it is extremely difficult to detect it. If prostate cancer is detected at an early stage, it can be successfully cured by different methods. At the later stages, treatment or surgery has very low efficiency. Prostate cancer can often be found by measuring the amount of PSA in the blood. Most healthy men have levels under 4 nano-grams per milliliter $(\mathrm{ng} / \mathrm{mL})$ of blood. When prostate cancer develops, the PSA level usually goes above 4. However, for determination of the existence of cancer, some additional methods are used: for example: PSA velocity [3,4] and/or PSA density. Besides, measurement of the ratio of free to total PSA is additional tool in prostate cancer diagnosis [5]. However, the major drawback of PSA determination is its relative lack of specificity. The PSA level can also be increased by benign prostate hyperplasia (BPH) - a noncancerous enlargement of the prostate, prostatitis, etc.

Digital rectal examination (DRE) is one of methods for prostate cancer diagnosis. The vast majority of prostatic carcinomas arise in the peripheral zone of the prostate. This part of the gland is accessible by DRE $[6,7]$. The DRE screening test for prostate cancer requires to assess the size, shape, and texture of the prostate and nearby organs. The sensitivity and specificity of a DRE examination is subject to a physician's skill, the clinician's ability to interpret what is felt, and the nature of the patient's disease. Although DRE can detect prostate cancer, it has limited sensitivity. Unfortunately, many cancers detected using DRE are either locally or regionally advanced. Prostate cancer may be identified on Trans-rectal ultrasound (TRUS) as a hypoechoic lesion. However, only $60 \%$ of prostate cancers appear hypoechoic on ultrasound while most of the remaining cancers appear isoechoic with respect to the surrounding parenchyma [8]. Because other disease processes, such as BPH and prostatitis may have a similar appearance to prostate cancer, it is impossible to reliably differentiate these lesions from prostate cancer based on ultrasonographic characteristics alone. Consequently, TRUS should not be used as a first line screening study as it lacks acceptable specificity.

The biopsy. At early stage of cancer, the needle may not even go where a cancer exists. So, it is common to have repeated biopsy being performed. And still, any cancer may go undetected. Biopsy is efficient if other methods reliably detect and locate the presence of suspicious areas $[9,10]$. If a man actually does have prostate cancer, a prostate biopsy usually releases cancer cells into the blood stream. These cancer cells then travel through the body where they can potentially colonize and grow. Thereby, biopsy correlates with the risk of disease extension and cancer progression. Besides, biopsy might cause complications: Typical prostate biopsy complications include painful infection, bloody semen, inability to urinate, bleeding rectum [11].

Magnetic resonance imaging (MRI) uses a powerful magnetic field, radiofrequency (RF) pulses and a computer to produce detailed pictures. MRI requires a radiologist and a physician specifically trained to supervise and interpret radiology examinations. MRI cannot always distinguish between cancer tissue and inflammation or presence of blood products 
within the prostate, which sometimes occurs related to a prostate biopsy [12]. Positron emission tomography (PET) is a technique that produces a three-dimensional image of functional processes in the body. The system detects pairs of gamma rays emitted indirectly by a positron-emitting radionuclide (tracer), which is introduced into the body on a biologically active molecule. Three-dimensional images of tracer concentration within the body are then constructed by computer analysis [13]. Prostate cancer antigen 3 (PCA3), also referred to as DD3 is a gene that expresses a non-coding RNA. But more research is needed to find exactly how much PCA3 in the urine is a sign of prostate cancer. The PCA3 test isn't yet accurate enough to be used on its own as a test for prostate cancer [14]. In recent years attention was directed to the possibility usage of infrared tomography as a new tool for prostate cancer visualization [15-17], however results are obtained on isolated prostates and there is a need for farther investigations on alive patients. .

\section{References}

1. http://www.who.int/mediacentre/factsheets/fs297/en/

2. Pernar CH, Ebot EM, Wilson KM, Mucci LA (2018) The epidemiology of prostate cancer. Cold Spring Harb Perspect Med 8(12): pii: a030361.

3. Balk SP, Ko YJ, Bubley GJ (2003) Biology of prostate-specific antigen. J Clin Oncol 21(2): 383-391.

4. Rao AR, Motiwala HG, Karim OM (2008) The discovery of prostatespecific antigen. BJU Int 101(1): 5-10.

5. Dinçel C, Caşkurlu T, Taşçi AI, Cek M, Sevin G, et al. (1999) Prospective Evaluation of Prostate Specific Antigen (PSA), PSA density, free-tototal PSA ratio and a new formula (prostate malignancy index) for detecting prostate cancer and preventing negative biopsies in patients with normal rectal examinations and intermediate PSA levels. Int Urol Nephrol 31(4): 497-509.

6. Figueirêdo Mde F, Lopes GT, Naidu TG (2003) Digital rectal examination (DRE) does not influence total serum levels of prostate specific antigen (tPSA), in individuals without prostate pathology. Int Braz J Urol 29(5): 423-427.
7. Catalona WJ, Richie JP, Ahmann FR, Hudson MA, Scardino PT, et al. (2017) Comparison of digital rectal examination and serum prostate specific antigen in the early detection of prostate cancer: Results of multicenter clinical trial of 6,630 men. J Urol 197(2S): S200-S207.

8. http://www.upmccancercenters.com/cancer/prostate/ biopsyultrasound.html

9. Natarajan S, Marks LS, Margolis DJ, Huang J, Macairan ML, et al. (2011) Clinical application of a 3D ultrasound-guided prostate biopsy system. Urol Oncol 29(3): 334-342.

10. van Hove A, Savoie PH, Maurin C, Brunelle S, Gravis G, et al. (2014) Comparison of image-guided targeted biopsies versus systematic randomized biopsies in the detection of prostate cancer: A systematic literature review of well-designed studies. World Journal of Urology 32(4): 847-858.

11. Squire LF, Novelline RA (1997) Squire's fundamentals of radiology. $\left(5^{\text {th }}\right.$ edn), Harvard University Press, Cambridge, Massachusetts, USA, ISNB 0-674-83339-2.

12. Eiber M, Nekolla SG, Maurer T, Weirich G, Wester HJ, et al. (2015) 68GaPSMA PET/MR with multimodality image analysis for primary prostate cancer. Abdom Imaging 40(6): 1769-1771.

13. Mauer T, Beer AJ, Souvatzoglou M, Holzapfel K, Kubeler H, et al. (2014) 72668 Gallium-labelled ligand of prostate-specific membrane antigen (PSMA) for the evaluation of recurrent prostate cancer using PET/CT andPET/MR imaging. European Urology Supplements 13(1): e726.

14. Roobol MJ, Schröder FH, van Leeuwen P, Wolters T, van den Bergh RC, et al. (2010) Performance of the prostate cancer antigen 3 (PCA3) genes and prostate-specific antigen in prescreened men: Exploring the value of PCA3 for a first-line diagnostic test. Eur Urol 58(4): 475-481.

15. Partsvania B, Khuskivadze A, Kochiashvili D, Koberidze G, Petriashvili G, et al. (2013) Near Infrared radiation in diagnosis of prostate cancer: Preliminary results. Urology 2(3): A1-A10, S1-S334.

16. Partsvania B, Tamaz S, Khuskivadze A, Shoshiashvili L, Ketevan C (2016) Infrared light enables visualization of the prostate carcinoma after radical prostatectomy. Oncology Discovery 4(2).

17. Khuskivadze A, Kochiashvili G, Partsvania B, Chubinidze K (2018) Polarized infrared light enables enhancement of histo-morphological diagnosis of prostate cancer. Australian Medical Journal 11 (9): 4544588.

For possible submissions Click below: 